\title{
A relação de cooperação (in)existe na Assistência Social: apontamentos sobre o Federalismo Brasileiro
}

The relationship of cooperation (in)exists in Social Assistance: briefing on Brazilian Federalism

\author{
GISELE APARECIDA BOVOLENTA (ㅇ
}

Universidade Federal de São Paulo, Santos, SP, Brasil.

RESUMO - Este texto ${ }^{1}$ se propõe a fazer uma reflexão, a partir de uma revisão bibliográfica, acerca do modelo federativo adotado no Brasil, tomando por base alguns pontos históricos, seus traços de permanências, mudanças e o impacto desse arranjo nas políticas sociais, em especial, junto à política de assistência social. Interessa-nos de modo direto, explorar o debate acerca da relação de cooperação entre os entes federados prevista no Pacto Federativo, de modo a identificar e compreender a sua (in)existência na gestão e na execução das políticas sociais.

Palavras-chave: Federalismo. Cooperação. Política de assistência social. Mudanças. Permanências.

ABSTRACT - This text proposes to reflect, based on a bibliographical review, on the federative model adopted in Brazil, based on some historical points, its traits of permanence, changes and the impact of this arrangement with social policies, specifically, together with Social assistance policy. We are entitled to debate the relationship of cooperation between federated entities provided for in the Federative Pact, in order to identify and understand their (in)existence in the management and execution of social policies.

Keywords: Federalism. Cooperation. Social assistance policy. Changes. Permanence. 


\section{Introdução}

$\mathrm{O}$ arranjo federativo brasileiro prevê uma relação de cooperação entre os entes federados no que tange a gestão e a execução das políticas sociais. No entanto, não é difícil identificar desafios e limitações que cotidianamente tensionam o cumprimento real dessas políticas. Ingerências políticopartidárias, relações de compadrio ou "troca de favores" são alguns exemplos que podem ser apontados como obstáculos do nosso federalismo. Somam-se a isso, os desequilíbrios políticos, econômicos e sociais entre os territórios e regiões do País que não foram superados, mesmo com a promulgação da Constituição Federal de 1988.

Conhecer a nossa histórica, as forças políticas e sociais, que ajudaram a formar o nosso sistema federativo nos permite identificar alguns traços que permanecem, bem como as mudanças e as transformações realizadas, e os seus respectivos impactos no cotidiano das políticas sociais. De modo específico, este texto traz algumas considerações a partir da política de assistência social.

Junto a isso, o texto busca ainda entender como se construiu o federalismo no Brasil, como chegamos ao chamado "Pacto Federativo" e como os entes da federação reconhecidos pós-Constituição Federal de 1988 - União, estados federados, Distrito Federal e municípios - cooperam (ou não) entre si, tomando por base a gestão e a execução de políticas sociais.

\section{Considerações sobre o federalismo na formação do Estado brasileiro}

Após a conquista do Brasil pelos portugueses, a primeira tentativa de organizar territorialmente essas terras ocorreu no século XVI, por meio das Capitanias Hereditárias. Na ocasião, o rei de Portugal, D. João III, dividiu a Colônia em 15 territórios, entregues a 12 donatários, pessoas agraciadas pelo Rei para explorar e cultivar o solo recém encontrado.

Portugal não dispunha de recursos suficientes para explorar as novas terras, assim a saída encontrada foi transferir essa incumbência principalmente para cavaleiros da pequena nobreza. $O$ vínculo jurídico entre o rei de Portugal e os donatários era estabelecido por Cartas de Doação (que conferiam a posse do território) e pela Carta Foral (que discriminava os direitos e deveres para exploração da terra recebida). Alguns direitos assegurados permitiam aos donatários redistribuir suas terras (as chamadas sesmarias) a quem pudesse cultivá-las. Os donatários podiam criar vilas e exercer sobre elas todo controle judicial e administrativo; além disso, os indígenas, considerados inimigos, poderiam ser escravizados e obrigados a trabalhar nas lavouras. Dos lucros advindos do comércio do pau-brasil, $5 \%$ deveriam ser entregues ao rei; e, com a morte do donatário, a terra passava para os seus descendentes. Dentre os deveres estabelecidos na Carta Foral estavam: assegurar $10 \%$ dos lucros sob todos os produtos existentes no território; um quinto dos lucros sob todos os metais e pedras preciosas encontrados; além de garantir o monopólio da exploração do pau-brasil à Coroa portuguesa.

A técnica de divisão do território nacional em Capitanias Hereditárias não obteve o sucesso esperado na tarefa de colonizar o Brasil. Apenas duas Capitanias floresceram: a de Pernambuco, capitaneada por Duarte Coelho, e a de São Vicente, capitaneada por Martim Afonso de Souza. As demais foram devastadas por ataques indígenas ou pela própria falta de recursos financeiros e inexperiência de seus donatários. Dos donatários encarregados de explorar, povoar e administrar seus lotes no Brasil, alguns não demostraram muito interesse em viver na Colônia, a fim de se empenharem no desenvolvimento da região, pois eram movidos apenas por interesses pessoais, visando enriquecimento em curto prazo. Assim, alguns deles nem sequem conheceram seus dotes (BALERA, 2013, p. 78).

Em 17 de dezembro de 1548 o rei português decretou a criação do Governo Geral do Brasil, sediado na Capitania da Bahia de Todos os Santos, escolhida por encontrar-se na Região Central da costa. 
No entanto, a distância que havia entre as Capitanias e o Governo Geral, e a oposição do poder local por homens que detinham posses (terras, gado e escravos), inviabilizaram o êxito dessa centralização de poder, fazendo com que o governador-geral só conseguisse resolver as dificuldades em âmbito local. Com o surgimento das primeiras vilas, formaram-se também as Câmaras Municipais, que cumpriam o papel de executar leis, cuidar do abastecimento do povoado, do sistema de tributação, da organização de expedições contra os indígenas, determinar a construção de novos povoados e definir os preços das mercadorias. O seu controle e a sua administração ficaram sob o comando dos chamados "homens bons", pessoas dotadas de posses e de poder que faziam frente ao governador-geral.

Em 1815 a Colônia foi elevada à condição de Reino Unido de Portugal, Brasil e Algarves, momento em que as Capitanias foram designadas como Províncias. A administração desses territórios, contudo, permanecia sob o comando dos capitães-gerais e governadores; somente em 1821, um ano antes da Independência, com a criação da Junta Provisória de Governos Independentes, é que esses responsáveis foram destituídos e extinguiu-se definitivamente o Sistema de Capitanias no País.

Com a Independência do Brasil, em 7 de setembro de 1822, como resposta às pressões exercidas pelas cortes portuguesas na recolonização do território brasileiro, havia 19 Províncias, algumas delas ocupadas por tropas lusas, onde existiam importantes forças contrárias ao processo de independência, especialmente em Grão-Pará, Maranhão, Bahia e Cisplatina. Os partidários das cortes na Bahia foram os que mais resistiram ao novo governo, o que foi superado apenas no final de 1823, após um período de conflitos, quando todas as Províncias foram incorporadas de fato ao Império brasileiro.

As elites regionais, empenhadas na defesa de seus interesses locais, tinham na autonomia das Províncias conquistas estratégicas para a condução de seus negócios e decisões, embora o poder central, sob o comando do imperador D. Pedro I, defendesse um Estado Nacional com a centralização das decisões e o controle das Províncias.

Dolhnikoff (2003, p. 117) narra a relação existente entre as elites regionais e o poder central na construção do Estado brasileiro durante o século XIX:

Maior autonomia significaria garantir aos grupos dominantes nas províncias um papel decisivo na condução do País. Questão que percorreu todo o século XIX e adentrou a república, quando passou a ser expressa nos frequentes debates sobre o federalismo brasileiro.

Sua narrativa investiga a relação construída entre as elites regionais (em busca de um Estado descentralizado) e o poder central (leal à centralização imperial), pontuando as articulações de ambos os lados em prol dos seus respectivos interesses.

A Constituição de 1824, outorgada por D. Pedro I, determinou as bases da estrutura política, da organização e do funcionamento do Império, estabeleceu o voto censitário, determinou a divisão políticoadministrativa das Províncias e instituiu quatro poderes: executivo, legislativo, judiciário e moderador (exercido de modo exclusivo pelo Imperador), definindo uma estrutura de governo baseado em uma monarquia hereditária, constitucional e representativa.

Os interesses das elites provinciais, sobretudo em razão do excessivo poder imperial, levaram a conflitos e revoltas em diversas Províncias do País, como a Cabanagem (Pará, 1835-40), a Sabinada (Bahia, 1837-38), a Balaiada (Maranhão, 1838-40) e a Farroupilha (Região Sul 1835-45). Outros episódios também contribuíram para a renúncia de D. Pedro I, como as disputas territoriais (como ocorreu na Província da Cisplatina entre o Brasil e as Províncias Unidas do Reino da Prata, atual Argentina), a abdicação do trono português com a morte de D. João VI, em 1826, e a falência do Banco do Brasil, em 1829. D Pedro I abdicouse do trono em favor de seu filho, na época menor de idade, que ficou aos cuidados de um tutor - José Bonifácio.

Até D. Pedro II atingir idade para assumir o trono, foi instituído no Brasil um sistema de regência (1831-40), considerado um dos períodos de maior agitação política do Brasil no século XIX, acentuando a polarização que mantinha, de um lado, os defensores de D. Pedro I e de um Estado centralizado e unitário, de outro, os que pretendiam acabar com o poder moderador, o senado vitalício, o conselho de Estado e 
garantir maior autonomia para as Províncias; alguns chegavam a defender, inclusive, a República e o sistema federativo e descentralizado de Estado. Havia ainda, outro grupo, considerado mais moderado, preocupado basicamente em manter a ordem interna e a integridade do território.

Dolhnikoff, apesar de reconhecer que a centralização teria prevalecido ao longo do século XIX, afirma que:

[...] um exame do funcionamento dos governos provinciais e suas relações com o governo central permite relativizar essa afirmação [...] [pois] A partir das reformas liberais da década de 1830, em especial a promulgação do Ato Adicional em 1834, o arranjo institucional prevalecente garantiu aos governos das províncias, através das assembléias legislativas, autonomia de decisão em relação a itens estratégicos como tributação, empregos, força policial, obras públicas, instrução pública, etc. (DOLHNIKOFF, 2003, p. 117).

A polarização entre Estado centralizado e descentralizado orientou grande parte das articulações e dos debates políticos durante o século XIX. A defesa em torno do federalismo centrava-se na busca por um sistema de governo central voltado para todos e atuando junto com os governos locais (ou regionais). Essa estrutura de governo inspirava-se na organização adotada pelos EUA após a conquista de sua independência, em 1775, que preservava a autonomia de cada estado ao mesmo tempo em que criava um poder central de interesse e de defesa de todos. Essa inspiração permitiu gerar movimentos em defesa de um sistema federalista no território brasileiro, sob o comando de líderes republicanos que comumente faziam comícios abertos a toda população em defesa da implantação da República.

Em 15 de novembro de 1889, a partir de um golpe militar liderado pelo Marechal Deodoro da Fonseca, foi proclamada a República no Brasil. São Paulo e Minas Gerais defendiam um modelo de governo inspirado no liberalismo, particularmente, os paulistas inspiravam-se ainda no modelo norte-americano de federalismo. O Rio Grande do Sul, por sua vez, era adepto dos ideais positivistas. Entre os militares também existiam diferentes correntes políticas. O governo provisório em vigência convocou uma Constituinte, que culminou na promulgação da 1aㅡ Constituição da República - liberal e federativa - em 1891.

A Carta Magna de 1891 assegurou um regime político presidencialista, apoiado nos poderes executivo, legislativo e judiciário; as Províncias foram elevadas a estados ${ }^{2}$, os quais poderiam constituir suas forças militares, estabelecer seus sistemas de tributação e eleger seus governadores.

A estrutura política no início da República criou um sistema de aliança baseado em uma rede de compromissos e lealdades, entre o governo federal, os governadores de estado e os líderes locais, conhecidos como coronéis, que marcou a Primeira República (1889-1930).

O exercício do clientelismo, do patrimonialismo, da "ideologia do favor", das redes de compadrio eram práticas recorrentes nesse contexto que mesclavam os interesses privados aos interesses públicos na teia das relações de poder ante a instância governamental, demarcando a presença e a permanência da lógica privada no interior da máquina pública. É possível considerar que tal lógica permanece, em maior ou menor grau, até os dias atuais; enquanto a herança portuguesa mostra que "O Estado seria a continuidade das relações privadas, faltando 'a tudo a ordenação impessoal'." (VELLASCO, 2009, p. 81). Desse comportamento se desdobram práticas mais atuais, mas similares à ingerência da lógica privada na instância pública, como, por exemplo, o "apadrinhamento", o "jeitinho" e a "carteirada”, criando relações (quase) personalistas que seguramente são um obstáculo na efetivação e no reconhecimento dos direitos de cidadania e da gestão das políticas públicas na perspectiva da universalidade.

Durante a Primeira República ocorreu a alternância de poder entre São Paulo e Minas Gerais, que eram, naquele momento, os estados mais ricos e populosos, e cujo momento ficou conhecido como "política do café com leite". Essa relação nem sempre era estável e equilibrada, por vezes havia conflito de interesses entre ambos de modo que, a cada sucessão presidencial, ela se refazia. Além disso, com poderes menores, mas compondo o cenário político, outros estados, como o Rio Grande do Sul, a Bahia e o Rio de Janeiro, destacavam-se e buscavam fazer frente a essa aliança. 
O surgimento da estrutura federativa no Brasil também não conseguiu estabelecer uma relação de interdependência entre a União e os estados. Havia um desequilíbrio federativo acentuado que contrapunha, de um lado, dois estados muito fortes - Minas Gerais e especialmente São Paulo - contra uma União frágil frente a eles, e de outro, mais de uma dezena de unidades estaduais que mal podiam sobreviver pelas "próprias pernas", necessitando de auxílio do Tesouro federal - o que na prática significava se filiar automaticamente ao bloco do "café com leite". Sem real autonomia para todos os estados, torna-se difícil implementar um verdadeiro federalismo.

A última consequência [...] é que o federalismo no Brasil surgiu dissociado da República. O federalismo da Primeira República foi o reino das oligarquias, do patrimonialismo e da ausência do povo no cenário político. Ou seja, anti-republicano por excelência (ABRUCIO, 1998, p. 40).

A insatisfação de grupos políticos do Rio Grande do Sul, de Minas Gerais e da Paraíba com as eleições de 1930, que mantinha um presidente paulista no poder, os levou, unidos a oficiais do Exército, a deflagrar a "Revolução de 1930" que, a partir de um Golpe de Estado, sob o comando de Getúlio Vargas, depôs o presidente Washington Luiz, impediu a posse de Júlio Prestes e colocou fim à "República Velha" (ou Primeira República). Vargas assumiu um "Governo Provisório", iniciando as primeiras legislações sociais e o estímulo ao desenvolvimento industrial.

A "Era Vargas" (1930-45), como ficou conhecida, "Era um modelo de Estado de acomodação de interesses, de compromisso entre setores e classes sociais" (ABRUCIO, 1998, p. 42). A base de apoio de Vargas não era homogênea, sendo composta por grupos reformistas, incluindo os tenentes, favoráveis à implementação de leis sociais e que apoiavam à diversificação da economia e defendiam reformas no País; por outro lado, haviam políticos conservadores que não defendiam tais reformas, temerosos de que os seus interesses fossem atingidos por elas.

Em 16 de julho de 1934 foi promulgada uma nova constituição para o País, que preservava os pilares básicos da composição da nação. O Brasil permanecia sendo uma República Federativa, com relativa autonomia para os estados e manutenção do sistema tripartite de poderes (Legislativo, Executivo e Judiciário).

O País vivia um período de intensos conflitos, que chegou ao ápice em 1935 com a insurreição comunista que provocou rebeliões em alguns locais, as quais foram controladas e sufocadas pelas forças do governo. A partir disso, houve uma forte repressão aos comunistas e às organizações de esquerda, com perseguição, prisão e maus-tratos de pessoas ligadas a esses movimentos, além de disseminar junto às Forças Armadas e à elite do País uma repulsa contra os comunistas. Esse episódio fortaleceu a figura de Getúlio Vargas a partir da ampliação de seus poderes, aprovada pelo Congresso Nacional, autorizando-o, inclusive, a reprimir manifestações políticas. Desse modo, adquiriu amplos poderes, com o apoio das Forças Armadas e das elites políticas, além do prestígio acumulado junto a certos setores, como trabalhadores e intelectuais.

Em 1937, Getúlio Vargas deu um golpe de Estado, iniciando a ditadura do "Estado Novo". Nele, o federalismo foi novamente posto em xeque, ocasião em que o então presidente excluiu o poder destinado aos estados, nomeando interventores para administrá-los e eliminando as eleições diretas para os governos estaduais. Foi, portanto, um governo impositivo, ditatorial, que diminuiu a autonomia do executivo estadual, praticamente extinguindo o sistema federalista.

A ditadura varguista só começou a declinar quando a democracia liberal recuperou seu o prestígio, após a Segunda Guerra Mundial, momento em que se inicia a transição de um regime ditatorial para um sistema democrático; isso levaria ao fim do "Estado Novo", em 1945.

No ano seguinte, em 1946, uma nova Constituição foi promulgada, assegurando a eleição direta para governadores, deputados e senadores, além de aumentar a autonomia política e financeira dos municípios. No entanto, cada vez mais se tornavam evidentes os desníveis entre os estados mais ricos e os mais pobres, fazendo com que esses últimos ficassem ainda mais dependentes do poder central. Esse desequilíbrio econômico acabou por contribuir para o enfraquecimento do sistema federativo no País. 
Getúlio Vargas retomou o poder em 1950, ficando até o seu suicídio, em 1954; em 1956 iniciou o governo de Juscelino Kubitschek (1956-1960), de caráter nacional-desenvolvimentista; em 1960, Jânio Quadros assumiu o cargo de presidente, tendo João Goulart (Jango) como seu vice. Com a perda de apoio parlamentar e instituindo medidas que geravam insatisfações, Jânio renunciou em 1961, tomando posse o seu vice, adepto do programa político conhecido pelas "Reformas de Base", o qual também era defendido pela esquerda do País. No entanto, o golpe militar de 1964 impediu o mandato de Jango, dando início a um dos períodos mais repressivos e violentos do Brasil: a ditadura militar, que durou 21 anos.

Nesse período o federalismo foi novamente interrompido, tendo o poder centralizado no executivo federal que governava por meio dos Atos Institucionais (A.I.). O Al-5 deu legalidade à truculência do regime e foi muito prejudicial aos estados federados, os quais tiveram a sua autonomia restrita através da intervenção federal decretada em 1968.

A reorganização do País trazida pela Constituição Federal de 1988 (ou Constituição Cidadã) consagrou o regime democrático no Brasil e apresentou importantes mudanças, avanços e conquistas, como o reconhecimento de direitos civis, políticos e sociais, além do fortalecimento de instituições e da sociedade civil. No entanto, a "Nova República" não conseguiu reparar antigas práticas e problemas socioeconômicos, como a enorme dívida pública, a corrupção, a inflação, o arrocho salarial, as desigualdades socioeconômicas, regionais e a enorme concentração de renda no País, problemas que, aliás, não se encontram plenamente solucionados até os dias atuais.

A Constituição Cidadã resgatou as bases de um Estado federal. A democratização e a descentralização definiram relações intergovernamentais entre a União, os estados federados, os municípios e o Distrito Federal, com autonomia, definição de responsabilidades e competências ante o Estado brasileiro. Esse arranjo prevê uma relação de cooperação e de equilíbrio entre os integrantes da federação, preservando os interesses específicos e comuns diante de um pacto firmado entre as partes.

O termo "federal" é derivado do latim foedus, o qual [...] significa pacto. Em essência, um arranjo federal é uma parceria, estabelecida e regulada por um pacto, cujas conexões internas refletem um tipo especial de divisão de poder entre os parceiros, baseada no reconhecimento mútuo da integridade de cada um e no esforço de favorecer uma unidade especial entre eles (ABRUCIO, 1998, p. 27, grifo do autor).

Os caráteres republicano e democrático de cooperação entre os estados-membros devem, portanto, prevalecer perante o pacto firmado, o que parece não ser a realidade do federalismo brasileiro, no qual impera um permanente conflito entre as forças regionais e o poder central.

Algumas críticas assertivas quanto à Constituição Cidadã de 1988 pontuam que houve o reconhecimento e a transferência de certos encargos aos estados federados e aos municípios sem proporcionar aos mesmos as condições para cumpri-los. Destaca-se que o Brasil possui mais de $70 \%$ de municípios pequenos (de até 20 mil habitantes), muitos dos quais não conseguem, mantêm todo funcionamento da máquina pública por meio de suas próprias receitas, salvo algumas exceções, o que os torna, em grande parte, dependentes dos estados e da União no repasse de recursos para prover as suas demandas locais. Soma-se a isso que, entre 1989 e 2007, o Brasil criou 1.364 municípios; desses, 1.287 tinham até 20 mil habitantes, os quais, em parte, cumpriam um papel estratégico de constituírem e alimentarem os "currais eleitorais".

Além disso, a Carta Magna não equalizou as condições socioeconômicas das 27 unidades governamentais, permanecendo grandes diferenças entre si, o que acabou acentuando a miséria e a pobreza de uns (basicamente dos estados que se encontram na região Norte e Nordeste) e o poder e a riqueza de outros (representados pelos estados no Centro-sul), ainda assim prevalecendo uma assimetria interna. Ou seja, havia (e permaneceu) um desequilíbrio econômico e político expresso nos territórios que impactou na desigual arrecadação de tributos e/ou na sistemática dependência de recursos, advindos de outras instâncias, criando uma relação pendular no peso político-econômico entre os entes federados e comprometendo o próprio sistema federativo.

Outra crítica em destaque revela que, desde a Constituinte os estados federados, ao que parece, não tiveram uma função muito definida junto à gestão pública, ao contrário dos municípios, que ganharam 
autonomia e compuseram o rol da descentralização político-administrativa: "[...] além da má definição de suas competências materiais, os estados também possuem pequena quantidade de competências legislativas próprias. Como afirma o jurista Celso Bastos, 'aos Estados, hoje não é dado legislar originariamente sobre quase nada'"' (ABRUCIO, 1998, p. 139). Dentro da federação, considera-se o membro com competências menos definidas, de modo que "[...] a indefinição das competências legislativas dos estados torna mais difícil para o cidadão saber quais são as reais atribuições do governo estadual" (ABRUCIO, 1998, p. 139), o que permite construir uma relação antirrepublicana e antidemocrática por excelência.

A relação de cooperação, portanto, firmada com o Pacto Federativo mostrou, desde o início, um desalinho entre compromissos e atribuições firmados entre as partes envolvidas. Os vários partidos criados (e a sua ausência de identidade) e os cargos públicos ocupados não correspondiam, em grande parte, às necessidades e à realidade de um "Estado democrático de direito"; os "puxadores de voto", os currais eleitorais, as relações clientelistas, apenas ilustram um sistema político fraco que cria (e mantém) estratégias de manutenção do poder não cooperativo, prevalecendo o individualismo e o imediatismo, como um "trampolim" para apoio e cargos políticos, não assumindo de fato importantes direitos sociais reconhecidos.

Alguns autores ${ }^{3}$ têm analisado o modelo de Estado Federativo brasileiro apontando as suas limitações e dificuldades para a gestão das políticas públicas. Marta Arretche, por exemplo, tem um acúmulo de análises e estudos acerca do federalismo no País; para a autora, "O Brasil é estruturalmente um país caracterizado pela existência de uma esmagadora maioria de municípios fracos, com pequeno porte populacional, densidade econômica pouco expressiva e significativa dependência de transferências fiscais" (ARRETCHE, 2000, p. 70).

Em outra reflexão, Arretche (2012) mostra a operação vertical do Estado federativo brasileiro, que “(...) combina ampla autoridade legislativa para a União com limitadas oportunidades institucionais para o veto dos governos subnacionais" (ARRETCHE, 2012, p. 17). Para Arretche a CF/88 descentralizou a execução das políticas sociais, mantendo a autonomia decisória centralizada na União.

Souza destaca ainda que,

Apesar de a Constituição prover vários mecanismos que sinalizam no sentido do federalismo cooperativo [...], o federalismo brasileiro tende a ser altamente competitivo e sem canais institucionais de intermediação de interesses e de negociação de conflitos (SOUZA, 2005, p. 114).

Para a autora, o objetivo do federalismo cooperativo está longe de ser alcançado e isso se daria por duas razões:

A primeira está nas diferentes capacidades dos governos subnacionais de implementarem políticas públicas, dadas as enormes desigualdades financeiras, técnicas e de gestão existentes. A segunda está na ausência de mecanismos constitucionais ou institucionais que estimulem a cooperação, tornando o sistema altamente competitivo (SOUZA, 2005, p. 112).

Esse cenário se agrava ao observar a "[...] simbiose entre público e privado [...]" (VELLASCO, 2009, p. 85) existente no País, mesclando a lógica pública com a privada, o que impacta diretamente no Pacto Federativo na medida em que se definem os elementos pessoais como condutores da relação de cooperação entre os entes. Isso é observado ao notar a prevalência de maior ou menor investimento e apoio por uma ou outra localidade conforme as alianças políticas constituídas. Por vezes, acima da relação de cooperação que o nosso sistema federativo prevê, encontram-se as relações de compadrio, alianças, "trocas de favores" etc. que caminham na contramão de um Estado Federativo.

Essas considerações, ainda que breves, contribuem para entender as dificuldades do nosso sistema federativo em cumprir o pacto de cooperação firmado, na mediada em que se observa a relação truncada entre os entes federados em afiançar direitos sociais de modo integrado e articulado. 


\section{A assistência social na Constituição Federal de 1988}

Com o reconhecimento da CF/1988, o País pactuou um Estado Democrático de Direito que retomava o sistema federativo, sequestrado durante o regime militar. A integralidade assegurada à política de assistência social, como parte do sistema de seguridade social, e a descentralização político-administrativa entre os entes federados em sua efetivação anunciavam o caráter de política integrada e articulada para efetivar um campo de proteção social de caráter distributivo ou não contributivo.

A autonomia e a cooperação dos entes federados na implementação da política de assistência social permitiram avanços na medida em que as especificidades locais e regionais foram reconhecidas. Aliás, como afirma Sposati: "Propostas homogeneizadoras são a antítese da história, da geografia do país e da trajetória dos que nele vivem em diferentes locais. Tratar igual o diferente implica em correr o risco de desenhar uma atenção no campo do destrato e não, do trato" (SPOSATI, 2015, p. 51).

Na Lei Orgânica da Assistência Social (LOAS) definiu-se a organização e a gestão da política estabelecendo as competências de cada ente federativo, com base na "[...] descentralização político-administrativa para os Estados, o Distrito Federal e os Municípios, e comando único das ações em cada esfera de governo". Seu campo de proteção social parte dessa relação de cooperação, no âmbito de um pacto, entre os entes da federação. Requer considerar, portanto, que há competências estabelecidas e específicas, cujas partes dependem e se apoiam mutuamente no cumprimento do dever público estatal. No âmbito do Sistema Único da Assistência Social (SUAS) "a gestão das ações na área de assistência social fica organizada sob a forma de sistema descentralizado e participativo", conforme assegura a Lei do SUAS (Lei no 12.435/11).

Tomando por base o financiamento da política, por exemplo, Sposati $(2015$, p. 55) destaca que

Entre as três instâncias estatais, em 2011, as maiores despesas com a rede socioassistencial são procedentes das gestões municipais, com exceção do crescente gasto federal com benefícios como Benefício de Prestação Continuada e de transferência de renda (Bolsa Família), cuja operação não está vinculada aos princípios operativos do SUAS.

A autora apresenta dados da pesquisa que mapeou as despesas do ente federativo municipal com a política de assistência social. Essa pesquisa foi realizada pelo Núcleo de Estudos e Pesquisas sobre Seguridade e Assistência Social (NEPSAS) da PUC-SP em pareceria com o Colegiado Nacional dos Gestores Municipais de Assistência Social (CONGEMAS) e mostrou a relação pendular entre as partes na estrutura orçamentária da política ante o Pacto Federativo, aspecto que precisa ser revisto a fim de avançar na consolidação do SUAS no País. De acordo com Sposati,

[...] o percentual do gasto com assistência social pelos municípios brasileiros tem entre si uma variação média e percentual de 2 a $4 \%$ no montante das despesas totais da Prefeitura de cada município. [...] Os governos estaduais aplicam percentual bastante inferior, somente $1 \%$ das despesas dos governos estaduais é destinada à assistência social. Enquanto os gastos das prefeituras, em 2011, somaram 10,5 bilhões de reais, os gastos dos estados com a mesma política somaram 4,1 bilhões. Em suma, o ente federativo estadual não tem apoiado a consolidação do SUAS. Quanto aos gastos federais, [...] a despesa em assistência social foi de 48,2 bilhões de reais em 2011 e de 56,6 bilhões em 2012 (SPOSATI, 2015, p. 58).

No SUAS, portanto, quem basicamente tem mantido o Sistema funcionando são os entes municipais e a instância federal. Em grande parte, a União vem mantendo os benefícios, como o Benefício de Prestação Continuada (BPC), e as transferências de renda, como o Programa "Bolsa Família"; e os municípios, mantêm os serviços socioassistenciais da política, deixando os estados federados em uma relação "frouxa" e com papel (quase) indefinido.

Essa assertiva vai ao encontro das análises de Gomes ao considerar que se encontra em andamento um novo Pacto Federativo na gestão da política de assistência social, em razão da efetivação do SUAS. Sua 
hipótese sugere que "[...] a implementação da descentralização da assistência social pública (portanto, pós-1988) vem ocorrendo, primordialmente sob o protagonismo mais forte das esferas municipal e federal, ao lado de um protagonismo mais incerto e secundário da esfera estadual" (GOMES, 2008, p. 5).

Além dos desequilíbrios já apontados, soma-se ainda o fato de

[...] que o processo de municipalização transformava-se facilmente na equivocada "prefeiturização", isto é, na sobrecarga de responsabilidades dos municípios, com a ausência de partilha de compromissos e financiamento com os demais entes federativos (GOMES, 2008, p. 13-14).

Ainda a título de exemplo, o benefício eventual (BE), reconhecido enquanto um direito na política assistência social, é uma provisão sob responsabilidade dos municípios, estados federados e Distrito Federal em uma relação de cooperação entre as partes quanto à gestão, à regulamentação e o financiamento; contudo ele permanece, em grande parte, sendo um "jogo de empurra" entre os entes envolvidos e negligenciado enquanto parte do campo de proteção social distributiva. Quando existente, conforme narrado em Bovolenta (2016), acaba centrando-se em âmbito municipal ${ }^{4}$. Não à toa, os municípios apontaram no Relatório sobre o Levantamento Nacional de Benefícios Eventuais realizado em 2009 pelo MDS e CNAS que uma das dificuldades na concessão do $\mathrm{BE}$, em $82 \%$, era a ausência de cofinanciamento do ente estadual no apoio a esse campo de atenção.

Esses apontamentos, ainda que breves, contribuem para identificar a formação do sistema federativo brasileiro ao longo da história e o Pacto Federativo na gestão da política de assistência social, no sentido de se compreender a estrutura construída para partilhar os encargos da gestão pública em uma relação de cooperação descentralizada. No entanto, as incongruências observadas na construção desse arranjo parecem ter the atribuído uma peculiaridade própria, prevalecendo os interesses das unidades acima da construção de um Estado Nacional de fato. Essa assertiva permite compreender a relação "mal resolvida" ou desequilibrada que por vezes se observa entre os membros da federação, a qual se desdobra na gestão das políticas sociais comprometendo direitos sociais legalmente reconhecidos.

É possível considerar ainda, que por vezes as ações da política de assistência social são concorrentes, paralelas ou sobrepostas, sobretudo em virtude dos arranjos político-partidários estabelecidos, pela ingerência privada junto à máquina pública, ou mesmo pela resistência em reconhecê-la como política pública, o que contribui por tensionar a sua execução de modo articulado e integrado em uma relação de cooperação como prevê o nosso arranjo federativo.

\section{Considerações finais}

Essa reflexão buscou compreender o arranjo federativo brasileiro, tomando por base alguns pontos de sua formação sócio-histórica e a realidade da política de assistência social. Sem esgotar o debate, as considerações apresentadas, ainda que breves, nos permitem compreender alguns traços, historicamente construídos, que impactam diretamente no cotidiano das políticas sociais.

Não é difícil identificar a ingerência privada junto à máquina pública, a relação de troca e favores, as alianças político-partidárias, entre tantas outras condutas que se colocam acima dos direitos sociais ou mesmo da impessoalidade da gestão pública. Parece fazer parte do cotidiano das políticas sociais as relações clientelistas de compadrio e apadrinhamento, que geram acessos diferenciados por parte dos cidadãos aos bens e serviços públicos, mesmo pós-Constituição Federal de 1988, a qual trouxe importantes avanços e conquistas para o País.

As críticas acerca do nosso arranjo federativo mostram a necessidade de fomentar esse debate, conhecê-lo e pensar alternativas que permitam que a gestão e a execução de políticas sociais estejam em conformidade com a garantia e o acesso aos direitos sociais. Longe da realidade truncada, sobreposta, concorrente, possível de ser observada no cotidiano dessas políticas, de modo específico, junto à política de assistência social. 
Defende-se, portanto, que essas considerações devam compor arenas de debates, sejam publicizadas e propulsoras de mudanças. Mudanças que permitam rever o nosso Pacto Federativo, de modo que as dificuldades enfrentadas pelo nosso arranjo federativo consigam ser superadas e, desse modo, permitam uma relação de cooperação entre os entes federados na gestão e execução de políticas sociais, o que na prática, parece ser inexistente, como este texto buscou mostrar.

\section{Referências}

BOVOLENTA, G. A. O benefício eventual da LOAS como garantia de proteção social. 2016. 303 f. Tese (Doutorado em Serviço Social) - Pontifícia Universidade Católica de São Paulo (PUC-SP), São Paulo, 2016.

ABRUCIO, F. L. Os Barões da Federação os governadores e a redemocratização brasileira. São Paulo: Hucitec, 1998.

ARRETCHE, M. Estado federativo e políticas sociais: determinantes da descentralização. Rio de Janeiro: Revan; São Paulo: FAPESP, 2000.

ARRETCHE, M. Democracia, federalismo e centralização no Brasil. Rio de Janeiro: FGV: Fiocruz, 2012. https://doi. org/10.7476/9788575415665

BALERA, F. P. Federalismo e as Possíveis Alterações no Território dos Estados Federados. Florianópolis: Conceito Editorial, 2013

BASTOS, C. A Federação no Brasil. Brasília, DF: Programa Nacional de Desburocratização; Instituto dos Advogados de São Paulo, 1985.

DOLHNIKOFF, M. O lugar das elites regionais. Revista da USP, São Paulo, n. 58, p. 116-133, jun./ago. 2003. https://doi. org/10.11606/issn.2316-9036.v0i58p116-133

DOLHNIKOFF, M. O pacto imperial: origens do federalismo no Brasil do século XIX. São Paulo: Globo, 2005.

GOMES, M. do R. Co. de S. Nacionalização da Política de Assistência Social e Governos Estaduais no Brasil: o caso do estado de São Paulo. 2008. 329 f. Tese (Doutorado em Serviço Social) - Pontifícia Universidade Católica de São Paulo (PUC-SP), São Paulo, 2008.

SPOSATI, A. Sistema Único: modo federativo ou subordinativo na gestão do SUAS. Katálysis, Florianópolis, v. 18, n. 1, p. 50-61, jan./jun. 2015. https://doi.org/10.1590/1414-49802015000100006

SOUZA, Celina. Federalismo, Desenho Constitucional e Instituições Federativas no Brasil pós-1988. Revista de Sociologia e Política, Curitiba, n. 24, p. 105-121, jun. 2005. https://doi.org/10.1590/S0104-44782005000100008

VELLASCO, I. de A. Clientelismo, ordem privada e Estado no Brasil oitocentista: notas para um debate. In: CARVALHO, J. M.; NEVES, L. M. B. P. (org.). Repensando o Brasil do Oitocentos: cidadania, política e liberdade. Rio de Janeiro: Civilização Brasileira, 2009. p. 71-99.

\section{Notas}

${ }^{1}$ Algumas reflexões apresentadas neste artigo foram trabalhadas em minha Tese de Doutorado em Serviço Social, defendida junto a PUC/SP em abril de 2016, a qual contou com apoio da Capes.

2 Neste momento eram 20 os estados reconhecidos, ampliados para 23 até 1988, quando a Constituição da República Federativa do Brasil de 1988 reconheceu 26 estados no Brasil, modo que permanece até os dias atuais.

${ }_{3}^{3}$ Dentre eles: FILHO, José dos Santos Carvalho. Pacto Federativo: aspectos atuais. Revista da EMERJ, Rio de Janeiro, v. 4, n. 15, p. 200-209, 2001; AFFONSO, Rui. A crise da federação no Brasil. Ensaios, Porto Alegre, v. 2, n. 15, p. 321-337, 1994; MARIANO, Jefferson. Políticas públicas e o pacto federativo. In: BONINI, Luci M. M.; PANHOCA, Ivone; CIANCIARULLO, Tamara Iwanow. Políticas públicas: estudos e casos. São Paulo: Ícone, 2014. p. 73-97; ALMEIDA, Maria Hermínia Tavares. Federalismo, Democracia e Governo no Brasil: Ideias, Hipóteses e Evidências. BIB, São Paulo, n. 51, p. 13-34, 2001; SOUZA, Celina. Federalismo, Desenho Constitucional e Instituições Federativas no Brasil pós-1988. Revista de Sociologia e Política, Curitiba, n. 24, p. 105-121, jun. 2005; ARRECTHE, Marta. Democracia, federalismo e centralização no Brasil. Rio de Janeiro: FGV; Fiocruz, 2012; HOCHMAN, Gilberto; FARIA, Carlos Aurélio Pimenta de (org.). Federalismo e políticas públicas no Brasil. Rio de Janeiro: Fiocruz, 2013; ABRUCIO, Fernando Luiz; SOARES, Márcia Miranda. Redes Federativas no Brasil: Cooperação Intermunicipal no Grande ABC. São Paulo: Fundação Konrad Adenauer, 2001. 
${ }^{4}$ Dado os limites de um artigo, não é possível aprofundar aqui a relação de cooperação (in)existente quanto a gestão, regulamentação e financiamento do benefício eventual. Para aprofundar esse debate ver: BOVOLENTA, Gisele Aparecida. O benefício eventual da LOAS como garantia de proteção social. Tese (Doutorado em Serviço Social) - Pontifícia Universidade Católica de São Paulo (PUC-SP), São Paulo, 2016.

Recebido em: 17/2/2018.

Aprovado em: 12/9/2018.

Publicado em: 10/10/2019.

Correspondência para:

Gisele Aparecida Bovolenta

Universidade Federal de São Paulo

DPPSC - Campus Baixada Santista

Rua Silva Jardim, 136 - Vila Mathias

11015-020, Santos, SP, Brasil

Autora:

GISELE APARECIDA BoVOLENTA

Doutora em Serviço Social pelo Programa de Pós-Graduação em Serviço Social da Pontifícia Universidade Católica de

São Paulo (PPGSS/PUCSP), São Paulo, SP, Brasil. Professora adjunta I no Curso de Serviço Social da

Universidade Federal de São Paulo (Unifesp), São Paulo, SP, Brasil.

Orcid: https://orcid.org/0000-0001-7413-1298

E-mail: gibovolenta@yahoo.com.br 